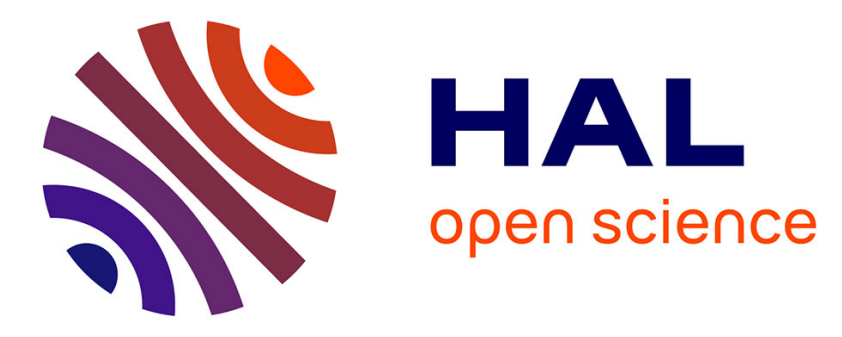

\title{
Experimental and Numerical Study of NH3/CH4 Counterflow Premixed and Non-premixed Flames for Various NH 3 Mixing Ratios
}

Sophie Colson, Yuta Hirano, Akihiro Hayakawa, Taku Kudo, Hideaki

Kobayashi, Cédric Galizzi, Dany Escudie

\section{To cite this version:}

Sophie Colson, Yuta Hirano, Akihiro Hayakawa, Taku Kudo, Hideaki Kobayashi, et al.. Experimental and Numerical Study of NH3/CH4 Counterflow Premixed and Non-premixed Flames for Various NH 3 Mixing Ratios. Combustion Science and Technology, In press, 10.1080/00102202.2020.1763326. hal-02994917

\section{HAL Id: hal-02994917 https://hal.science/hal-02994917}

Submitted on 23 Nov 2020

HAL is a multi-disciplinary open access archive for the deposit and dissemination of scientific research documents, whether they are published or not. The documents may come from teaching and research institutions in France or abroad, or from public or private research centers.
L'archive ouverte pluridisciplinaire HAL, est destinée au dépôt et à la diffusion de documents scientifiques de niveau recherche, publiés ou non, émanant des établissements d'enseignement et de recherche français ou étrangers, des laboratoires publics ou privés. 


\title{
Experimental and numerical study of $\mathrm{NH}_{3} / \mathrm{CH}_{4}$ counterflow premixed and non-premixed flames for various $\mathrm{NH}_{3}$ mixing ratios
}

\author{
Sophie Colson ${ }^{*}, 2,3$, Yuta Hirano ${ }^{1}$, Akihiro Hayakawa ${ }^{1}$, Taku Kudo ${ }^{1}$, \\ Hideaki Kobayashi ${ }^{1}$, Cédric Galizzi ${ }^{3}$, Dany Escudié ${ }^{3}$
}

${ }^{1}$ Institute of Fluid Science, Tohoku University, 2-1-1 Katahira, Aoba-ku, Sendai 980-8577, Japan

${ }^{2}$ Department of Aerospace Engineering, Tohoku University, 6-6-01 Aoba, Aramaki-aza, Aobaku, Sendai, Miyagi 980-8579, Japan

${ }^{3}$ Univ Lyon, CNRS, INSA-Lyon, Université Claude Bernard Lyon1, CETHIL UMR5008, F69621, Villeurbanne, France

* Sophie Colson

Institute of Fluid Science, Tohoku University, 2-1-1 Katahira, Aoba-ku, Sendai 980-8577, Japan (+81) $022-217-5273$

sophie.colson@insa-lyon.fr

ORCID Id: https://orcid.org/0000-0001-9968-0226 


\title{
Experimental and numerical study of $\mathrm{NH}_{3} / \mathrm{CH}_{4}$ counterflow premixed and non-premixed flames for various $\mathrm{NH}_{3}$ mixing ratios
}

\begin{abstract}
Ammonia is a promising sustainable fuel, however, its low reactivity creates challenges in industrial applications. In this study, ammonia/methane mixtures were considered for premixed and non-premixed counterflow flames. The extinction stretch rate was measured over a wide range of ammonia/methane mixing ratios and compared to $1 \mathrm{D}$ numerical results from four different mechanisms. Additionally, for counterflow premixed twin flames, quantitative analysis based on the comparison of experimental and numerical FWHM of $\mathrm{OH}$ and NO profiles was performed. Results showed that in premixed flames, all the mechanisms investigated were inadequate for predicting the extinction stretch rate, specifically for lean flames. In non-premixed flames, Okafor's mechanism was accurately predicting the extinction stretch rate. For the FWHM analysis, the numerical mechanisms overpredicted both $\mathrm{OH}$ and $\mathrm{NO}$ apparition in the flame, except for Tian's mechanism which underpredicted OH apparition. GRI Mech 3.0 performed well for small quantities of ammonia but failed to reproduce the pure ammonia case. Okafor's and UCSD mechanisms gave better predictions of experimental trends, though overestimated both $\mathrm{OH}$ and $\mathrm{NO}$ apparition. In the FWHM analysis of both $\mathrm{OH}$ and $\mathrm{NO}$, the lower $R^{2}$ values in the lean region suggest that the lean region should be the focus for mechanism improvement.
\end{abstract}

Keywords: $\mathrm{NH}_{3} ; \mathrm{CH}_{4}$; counterflow flames; flame stretch; extinction; PLIF

\section{Introduction}

Renewable energy resources are playing an important role in the future of energy production. However, the transportation and the storage of this energy remain challenging (Grand et al., 2016). One solution is chemical storage using green energy carrier fuels, such as hydrogen $\left(\mathrm{H}_{2}\right)$ and ammonia $\left(\mathrm{NH}_{3}\right)$. Because ammonia has a high hydrogen weight ratio of $17 \%$, it is seen as a promising hydrogen energy carrier (Kobayashi et al., 2019, Kojima 2015). Ammonia can be produced from nitrogen and water using the 
electricity obtained from renewable energy resources. The hydrogen produced from water-electrolysis is combined with nitrogen to produce ammonia using the Haber-Bosh process. Moreover, the existing ammonia storage and transportation network facilitates the large scale deployment of ammonia energy usage in the near future.

When compared to hydrogen, ammonia, although considered to be toxic, is safer to transport and store due to its thermal properties (Valera-Medina et al., 2018, Kobayashi et al., 2019). The high auto-ignition temperature of ammonia fuel prevents major incidents such as explosions and ammonia leakage can be easily detected due to its characteristic smell. This makes ammonia a promising fuel in the power and industrial sectors. Moreover, its production costs are comparable to those of conventional fuels (Avery, 1988). Ammonia can also be used as a fuel and its combustion yields no carbon emissions. An application of pure ammonia combustion in power generation has been recently demonstrated by AIST-FREA (Kurata at al., 2019; Okafor et al., 2019) generating $50 \mathrm{~kW}$ power, and showing that ammonia flame can be stabilized successfully in a gas turbine combustors using a regenerative cycle.

However, for various applications, ammonia combustion remains challenging due to low flammability and NOx emissions. To mitigate the issues related to its low flammability, hydrogen addition (Ichiwaka et al., 2015, Kumar and Meyer, 2013), oxygen-enriched combustion (Mei et al., 2019, Xia et al., 2020) and preheated-air combustion (Lhuillier et al., 2020) have been proposed and attempted. The addition of ordinary hydrocarbons as well as hydrogen is effective to improve flame stabilization and the gradual introduction of ammonia in existing large scale GTCC (gas turbine combined cycle) systems is possible. Most of the studies on ammonia/methane mixtures focused on small additions of $\mathrm{NH}_{3}$ to methane $\left(\mathrm{CH}_{4}\right)$ flames with the reduction of $\mathrm{NOx}$ emissions as their purpose (Banna and Branch, 1981, Sullivan et al., 2002, Rahinov et al., 2006, 
Mendiara and Glarborg, 2009, Zieba et al., 2009, Barbas et al., 2013 or Brackmann et al., 2018), while studies on larger quantities of $\mathrm{NH}_{3}$ remain limited to studies such as (Okafor et al., 2018, Ku et al., 2018, Somarathne, 2019). Thus, to develop efficient combustion systems for $\mathrm{NH}_{3} / \mathrm{CH}_{4}$ mixtures, fundamental flame characteristics and detailed chemistries should be carefully investigated.

A recent study by Okafor et al. (2018) on the laminar burning velocity of $\mathrm{NH}_{3} / \mathrm{CH}_{4} /$ air flames at atmospheric pressure resulted in the improvement of a kinetic mechanism for $\mathrm{NH}_{3} / \mathrm{CH}_{4} /$ air mixtures. This mechanism was validated based on the laminar burning velocities of mixtures having up to $50 \%$ of $\mathrm{NH}_{3}$ content in fuel mole fraction ratios, and over a range of equivalence ratios between 0.8 and 1.3. Such mixtures have also been studied in a high-pressure environment and a reduced mechanism was proposed based on measurements of the laminar burning velocity (Okafor et al., 2019).

In addition to the laminar burning velocity, the extinction stretch rate of counterflow flames, which is a predominant parameter of flame strength in turbulent flows (Escudié et al., 1999), and profiles of particular species are important data to validate and develop the combustion chemistry. The authors' group performed experiments to measure flame extinction for $\mathrm{NH}_{3}$ /air counterflow premixed flames at elevated pressure up to $0.5 \mathrm{MPa}$ and compared with that for $\mathrm{CH}_{4} /$ air flame (Colson et al., 2016). It was found that flame stretch rate at the flame extinction for $\mathrm{NH}_{3} /$ air flame is smaller than that for $\mathrm{CH}_{4} /$ air flames. However, when pressure rises, the extinction stretch rate increases significantly for $\mathrm{NH}_{3}$ /air flames compared to $\mathrm{CH}_{4}$ /air flames due to the differences in the effect of pressure on the major heat-releasing reactions of the chemical reaction paths of both flames (Colson et al., 2016). Studies on methane and hydrogen-doped ammonia nonpremixed counterflow flames were also performed by Choi et al. (2015) and $\mathrm{Ku}$ et al. 
(2018) showing large discrepancies between modeling and experimental data and the need for more detailed studies on those flames.

As for the species profiles, $\mathrm{OH}$ and $\mathrm{NO}$ play a key role in ammonia combustion characteristics such as ignition delay time, laminar burning velocity, extinction stretch rate and NOx production/consumption (Mathieu and Petersen, 2015, Colson et al., 2016, Okafor et al., 2018 and Kobayashi et al., 2019). The $\mathrm{OH}$ reactions with $\mathrm{NH}_{3}$ and $\mathrm{NH}_{2}$ through $\mathrm{NH}_{3}+\mathrm{OH}=\mathrm{NH}_{2}+\mathrm{H}_{2} \mathrm{O}$ and $\mathrm{NH}_{2}+\mathrm{OH}=\mathrm{NH}+\mathrm{H}_{2} \mathrm{O}$ account for around $23 \%$ of the total heat released in a stoichiometric $\mathrm{NH}_{3} /$ air premixed flames at ordinary pressure, and remains major in both rich and lean conditions (Colson et al., 2016). Moreover, around $16 \%$ of total heat is released by consumption of $\mathrm{NO}$ through $\mathrm{NH}_{2}+\mathrm{NO}=\mathrm{N}_{2}+$ $\mathrm{H}_{2} \mathrm{O}$ and $\mathrm{NH}+\mathrm{NO}=\mathrm{N}_{2} \mathrm{O}+\mathrm{H}$ (Colson et al., 2016) which occur in the flame front, where a large amount of $\mathrm{NO}$ upstream of $\mathrm{OH}$ radicals was observed by numerical simulations (Kobayashi et al., 2019). Furthermore, NO is a pollutant appearing in ammonia combustion and is thus of particular interest. While the extinction stretch rate provides a global approach to detailed chemistry validation, $\mathrm{OH}$ and $\mathrm{NO}$ profiles allow for the identification of the subsets of reactions that impact both emissions and flame extinction. OH-PLIF and NO-PLIF are well-known techniques to measure $\mathrm{OH}$ and $\mathrm{NO}$ profiles in flames (Battles and Hanson, 1995, Brackmann et al., 2016). Quantitative PLIF is challenging because of the multiple dependencies of the fluorescence signal. However, the PLIF method can be applied for $\mathrm{OH}$ and $\mathrm{NO}$ profiles by careful consideration of those dependencies, in the relatively simple cases of steady counterflow flames.

The objective of this study is to investigate the extinction stretch rates of both nonpremixed $\mathrm{NH}_{3} / \mathrm{CH}_{4}$-air and premixed $\mathrm{NH}_{3} / \mathrm{CH}_{4} /$ air counterflow twin flames for mixture over a wide range of equivalence ratios and $\mathrm{NH}_{3} / \mathrm{CH}_{4}$ mixing ratios at ordinary pressure. The experimental results were then compared to $1 \mathrm{D}$ numerical simulations using a set of 
mechanisms available in the literature. In addition, measurements of $\mathrm{OH}$ and $\mathrm{NO}$ profiles in $\mathrm{NH}_{3} / \mathrm{CH}_{4} /$ air counterflow premixed twin flames were performed using OH-PLIF and NO-PLIF. The measured FWHM (Full-Width-Half-Maximum) of OH and NO profiles from the PLIF images, which correspond to the distance between the two twin flames fronts, were compared to the ones obtained from numerical simulations with the selected mechanisms, considering quenching and temperature dependence.

\section{Experimental and numerical method and procedures}

[Figure 1]

The experimental setup consists of two identical opposing jet burners as shown in Fig.1 and described in further detail by Kobayashi and Kitano (1991). The outlet diameter of the two burners, $D$, was $10 \mathrm{~mm}$. From previous study on $\mathrm{NH}_{3} /$ air premixed counterflow flames (Colson et al., 2016), the distance between the two burners, $L$, has to remain sufficiently short to ensure flame stability over the full range of $\mathrm{NH}_{3}$ mixing ratios considered, even in flames with high ammonia concentration, and hence lower reactivity, for which buoyancy is more significant. However, for high velocities at the burner outlet, a short distance between the burners might affect the shape of the velocity profile at the outlet. Thus, to ensure good modeling of the present experimental configuration through the 1D numerical simulations, PIV (Particle Image Velocimetry) measurements were performed in both premixed and non-premixed flame configurations.

From the PIV results, it could be observed that the velocity at the burner outlet is slightly lower on the burner axis than on its surroundings, as presented in Fig.2. This is due to slightly elevated static pressure area appearing around the stagnation point as discussed in (Lindstedt et al., 2005) and (Davis et al., 1999). The velocity at the burner outlet is thus lower across the central axis of the burner than in the surrounding area, affecting the stretch rate seen by the flame. The relationships between the experimental 
bulk velocity obtained from mass flow meter measurements, $U$, and the velocity on the burner axis at the outlet, $U_{z 0}$, as well as the radial velocity gradient, $g_{r}$, were obtained from the PIV measurements as shown in Fig.2 for a broad range of velocities $U$, and for various fuel mixtures and equivalence ratios. $U_{z 0}$ and $g_{r 0}$, as well as $L$, were then considered as input parameters for velocity boundary conditions in numerical analysis.

[Figure 2] [Table 1]

In the present study, $L$ was selected as 10 and $12 \mathrm{~mm}$ depending on the experiments as shown in Table 1 which summarizes the geometric configurations. These selected trade-off values of $L$ gave geometric ratios, $L / D$, of 1.0 and 1.2. The chemical compositions of the fuel mixtures for both premixed and non-premixed flames are characterized by the $\mathrm{NH}_{3}$ mixing ratio based on lower heating values, $E$, as defined in Eq. (1), considering the mole fraction, $X_{i},\left(i=\mathrm{NH}_{3}\right.$ and $\left.\mathrm{CH}_{4}\right)$ and the low heat value, $L H V_{\mathrm{i}}$, of both $\mathrm{CH}_{4}\left(L H V_{\mathrm{CH} 4}=802.3 \mathrm{~kJ} / \mathrm{kmol}\right)$ and $\mathrm{NH}_{3}\left(L H V_{\mathrm{NH} 3}=316.8 \mathrm{~kJ} / \mathrm{kmol}\right)$.

$$
E=\frac{L H V_{\mathrm{NH}_{3}} \cdot \mathrm{X}_{\mathrm{NH}_{3}}}{L H V_{\mathrm{NH}_{3}} \cdot \mathrm{XNH}_{3}+\mathrm{LHV}_{\mathrm{CH}_{4}} \cdot \mathrm{X}_{\mathrm{CH}}}
$$

\subsection{Measurements of extinction stretch rate of counterflow flames}

For the counterflow premixed flames, the flame extinction was experimentally observed by keeping $E$ and $\phi$ constant while increasing the flow rates gradually for both burners as described in a previous study (Colson et al., 2016). The extinction stretch rate for the premixed flames was calculated using the values of the bulk velocities at the nozzle outlet at extinction, $U_{e x t}$, and $L$. This was then converted using the expression as in Eq. (2), which relates the axial velocity gradient upstream of the flame front, $\varepsilon$, which is equivalent to the stretch rate, with the global strain, $2 U_{\text {ext }} / L$, taking into account the 
geometric ratio, $L / D$. This expression was obtained from LDV (Laser Doppler

Velocimetry) measurements on the same burner by Kobayashi and Kitano (1991).

$$
\varepsilon=\left(0.73 \cdot\left(\frac{L}{D}\right)+0.5\right) \cdot\left(\frac{2 U_{e x t}}{L}\right)
$$

In the case of non-premixed flames, the extinction was observed by increasing $U$ while keeping the bulk velocity balance, such that $U_{o x}=U_{f u e l}$, for various $E$. The extinction stretch rate was then calculated from Eq. (3) (Seshadri and Williams, 1978),

$$
\varepsilon=\frac{2 U_{z 0, o x}}{L}\left(1+\frac{U_{z L, f u e l}}{U_{z 0, o x}} \sqrt{\frac{\rho_{\text {fuel }}}{\rho_{\text {ox }}}}\right)
$$

with $U_{z 0, o x}=1.202 \cdot U_{o x}$ and $U_{z L, f u e l}=0.851 \cdot U_{f u e l}$, where $U_{o x}$ and $U_{\text {fuel }}$ are air and fuel velocities at the burner outlet and the constants of 1.202 and 0.851 were taken from the PIV measurements in this study. $\rho_{\mathrm{ox}}$ and $\rho_{\text {fuel }}$ are the density of air and fuel, respectively. The uncertainty of the thermal mass flow meters employed in this experiments is within $1 \%$, leading to a systematical uncertainty of less than $2 \%$ in the evaluation of the equivalence ratio, $\phi$, and the fuel mixing ratio, $E$. The uncertainty in the evaluation of $U_{z 0}$ from the PIV measurement was of the order of $5 \%$, which in turn lead to same order of uncertainty in the calculation of $\varepsilon$.

The present experimental results on extinction stretch rates of $\mathrm{CH}_{4}$ premixed and non-premixed flames were in agreement with those available in the literature (Law et al., 1986, Takita et al., 2006, Chelliah et al., 1990) as presented in the later sections 3.1 and 3.2 (Figs. 5 and 6), validating the methodology.

\subsection{OH-PLIF and NO-PLIF measurements}

Profiles of $\mathrm{OH}$ and $\mathrm{NO}$ along the burners' axis were obtained using PLIF measurements. For the OH-PLIF, the laser beam was generated using an Nd-YAG pulsed 
laser (Spectra-Physics GCR-250-10 at $532 \mathrm{~nm}$ ) pumping a dye laser (Lumonics HD-500 for Rhodamine 6G) tuned at $565.858 \mathrm{~nm}$ and frequency-doubled (Lumonics HT-1000) at $282.929 \mathrm{~nm}$ to excite the $\mathrm{OH} \mathrm{A}{ }^{2} \Sigma^{+} \leftarrow \mathrm{X}^{2} \Pi(1,0)$ band with an energy of about $12 \mathrm{~mJ}$ per shot. The fluorescence was collected at approximately $310 \mathrm{~nm}$ using an intensified charge-coupled device camera (Andor iStar CCD) mounted with UV lenses (UV-Nikkor $105 \mathrm{~mm} \mathrm{F4.5)} \mathrm{with} \mathrm{a} \mathrm{combination} \mathrm{of} \mathrm{a} \mathrm{UG-11} \mathrm{filter} \mathrm{and} 313 \mathrm{~nm}$ band-pass filter.

For the NO-PLIF, the beam was generated using an Nd-YAG pulsed laser (SpectraPhysics GCR-250-10 at $355 \mathrm{~nm}$ ) pumping a dye laser (Sirah with a doubling unit for Coumarin 450) tuned at $452.596 \mathrm{~nm}$, frequency-doubled at $226.298 \mathrm{~nm}$ for excitation of the NO $A^{2} \Sigma \leftarrow X^{2} \Pi(0,0)$ band. The effectiveness of the Coumarin dye degrading with time, the energy was measured for every flame case, and considered in post-processing. The energy varied in the range $1-6 \mathrm{~mJ}$ per shot, corresponding to the linear fluorescence regime. A band-pass filter centered at $236.3 \mathrm{~nm}$ was used for fluorescence collection.

In both OH-PLIF and NO-PLIF, the beams were expanded through a set of UV cylindrical lenses to create a laser sheet of approximately $50 \mathrm{~mm}$ in height and $60 \mu \mathrm{m}$ thickness. The energy uniformity of the laser sheet was observed by the mean of fluorescence using an acetone cell. Settings for fluorescence collection through the ICCD camera were kept identical between each subset of pictures, to allow for the comparison between each flame case and with the simulated profiles from numerical analysis.

The images of OH-PLIF and NO-PLIF were first time-averaged over 250 raw images of the same flame case. The region of interest for comparison of the experimental profiles with numerical simulations being the burners axis, and the counterflow flames experimentally observed being curved only far from the axis, as seen in Fig.1, the fluorescence intensity profiles of $\mathrm{OH}$ and $\mathrm{NO}$ were then taken from the time-averaged image by spatially averaging across a 10 pixels width running perpendicular to the burner 
axis. This region is represented by a red box in Fig.1. Background images were processed in the same way and subtracted. A correction factor obtained with the acetone cell for the laser sheet energy profile was then applied.

The FWHM (Full-Width-Half-Maximum) of the PLIF intensity profiles, corresponding to the width at which the signal is $50 \%$ of its maximum value, were then used for comparison with the numerical analysis. It was found that variations of the FWHM calculated shot by shot remained under $10 \%$ for all cases considered. Spatial resolution was about $60 \mu \mathrm{m} / \mathrm{pixel}$. An example of normalized PLIF profiles and numerical simulation results for $\mathrm{OH}$ and NO profiles using Okafor's mechanism (Okafor et al, 2018) is provided in Fig.3 for rich $\mathrm{NH}_{3} /$ air flames. Because the present OH-PLIF and NO-PLIF are not simultaneous, the centers of the $\mathrm{OH}$ and NO profiles, i.e. the stagnation plane, are not strictly identical due to slight changes in the flow balance between the burners when reproducing the experiment. The error introduced remains small and is evaluated by the standard deviation on the FWHM for the reproduction of the same case and summarized in the supplementary material section. It is also clearly seen in Fig. 3 that for this flame case, the NO profile presents two peaks, also observable by numerical analysis with this mechanism, and that $\mathrm{NO}$ is present upstream of $\mathrm{OH}$. For the comparison of the FWHM of these $\mathrm{OH}$ and $\mathrm{NO}$ experimental profiles with the numerical one, careful considerations on quenching and temperature dependencies are essential and are argued in the section of results and discussions.

[Figure 3]

\subsection{Numerical procedures}

The numerical analysis was performed using the Chemkin-Pro software (Chemkinpro, 2010) with the opposed-flow model. In this study, detailed mechanisms for $\mathrm{NH}_{3}$ and 
$\mathrm{CH}_{4}$ combustion were selected according to the set of species they contained $\left(\mathrm{C}_{1}-\mathrm{C}_{2}\right.$ hydrocarbon species and $\mathrm{N}$ species with at least $\mathrm{NH}_{3}$ and $\mathrm{NOx}$ species) and validation reports available in the literature. Finally, the four following mechanisms were selected:

- The University of California, San Diego (UCSD) mechanism (University California San Diego, 2016) constitutes of 70 species and 321 reactions. It was initially designed for predicting hydrocarbon flames behavior but contains a large subset of nitrogen reactions and of hydrocarbon-nitrogen interactions reactions.

- Okafor's mechanism (Okafor et al., 2018) constitutes of 59 species and 356 reactions and is based on GRI Mech 3.0, with additional reactions and species from Tian's mechanism for $\mathrm{NH}_{3} / \mathrm{CH}_{4}$ mixtures. It has been well-validated for the prediction of the laminar burning velocity of such mixtures.

- GRI Mech 3.0 (Smith et al., 2000) is composed of 53 species and 325 reactions. Although GRI Mech 3.0 is most prevalent in methane flame studies, it does contain some nitrogen species, including $\mathrm{NH}_{3}$. GRI Mech 3.0 lacks some important ammonia oxidation steps but adequately reproduces the experimental laminar burning velocity of pure $\mathrm{NH}_{3}$ flame (Hayakawa et al., 2015).

- Tian's mechanism (Tian et al., 2009) constitutes of 84 species and 702 reactions. It was initially developed for $\mathrm{CH}_{4} / \mathrm{NH}_{3} / \mathrm{O}_{2} / \mathrm{Ar}$ flames and hence includes a complete set of $\mathrm{C}-\mathrm{N}$ interaction reactions. It is moreover well-validated in relation to the extinction stretch rate of $\mathrm{NH}_{3}$ /air premixed flames (Colson et al., 2016).

The transport and thermal properties are taken from University California San Diego, (2016), Okafor et al., (2018), Smith et al., (2000). For Tian's mechanism, transport and thermal data were obtained from private communication with Pr. Glarborg (Mendiara and Glarborg, 2009) with the addition of $\mathrm{C}$ specie thermal data from GRIMech 3.0 from Smith et al., (2000). 


\section{Results and discussion}

\subsection{Extinction stretch rate of counterflow premixed flames}

Experimental results on the extinction stretch rate, $\varepsilon_{e x t}$, of the counterflow premixed flames for various equivalence ratios, $\phi$, and $\mathrm{NH}_{3}$ mixing ratios, $E$, are presented in Fig.4. For all the $E$ considered, $\varepsilon_{e x t}$ increases when the $\phi$ increases, up to a maximum between $\phi=0.9-1.0$ and then decreases in the rich region. The maximum position in the lean region might be attributed to a non-equidiffusive phenomenon combined with stretch effect as stated by Law (2006). Both $\mathrm{NH}_{3} /$ air and $\mathrm{CH}_{4} /$ air lean mixtures have a Lewis number, $L e$ (= thermal to mass diffusivity) $<1$, whereas for rich mixtures, $L e>1$, as summarized in Table 2. In counterflow flames, the positive stretch is thus expected to enhance the flame temperature in the lean region for $L e<1$, and to lower it in the rich region for $L e>1$, leading to a maximum extinction stretch rate in the leaner region.

[Table 2] [Figure 4]

The experimental $\varepsilon_{e x t}$ of premixed counterflow flames and the numerical ones obtained from the four detailed chemistries selected are presented in Fig. 5. $\varepsilon_{\text {ext }}$ is plotted as a function of $E$ for three specific equivalence ratios corresponding to a lean case at $\phi=0.7$, the maximum extinction stretch rate at $\phi=0.9$ and a rich case at $\phi=1.2$. Data from $E=0.4$ to close to $E=1.0$ could not be collected in rich flames for which the control of smaller and simultaneous flow rates of $\mathrm{NH}_{3}$ and $\mathrm{CH}_{4}$ would have led to too large uncertainties in flow rate measurements. From Fig. 5, it can be observed that an increase in $E$ led to a decrease in $\varepsilon_{e x t}$, corresponding to the lower combustion intensity of ammonia flame. Experimental data for $\phi=0.9$ are well fitted into one curve, whereas there is more uncertainty for the data at $\phi=0.7$ and $\phi=1.2$. This larger scattering might be attributed to experimental limitations as buoyancy becomes more important for smaller values of $\varepsilon$. 
Of the four mechanisms, none were able to accurately reproduce the experimental trend over the considered range of $\phi$ and $E$ values. Larger discrepancies were observed for lean cases between experimental and numerical results, and also between mechanisms.

[Figure 5]

The discrepancies between experimental and numerical results are reduced as the equivalence ratio is increased until up to $\phi=1.2$, at which point all mechanisms are in reasonable agreement with the experimental results. The greatest discrepancies were observed for the pure $\mathrm{CH}_{4}$ case $(E=0)$ at $\phi=0.7$, and might be attributed to some limitations of the hydrocarbon subsets of the mechanisms selected in this study and is further developed in the supplementary material section. Apart from the pure $\mathrm{NH}_{3}$ case $(E=1.0)$, Tian's mechanism underestimates $\varepsilon_{e x t}$ for small $E$ as seen in Fig.5. This can be partially explained by the differences in the $\mathrm{HCO} \rightarrow \mathrm{CO}$ reaction step when compared to the other mechanisms as discussed by Okafor et al. (2018). Competition between the reactions of conversion of $\mathrm{HCO}$ to $\mathrm{CO}$ in the Tian's mechanism leads to a reduction in the production of the $\mathrm{H}$ radicals, lowers the flame reactivity and thus the extinction stretch rate. GRI Mech 3.0 systematically underestimates $\varepsilon_{\text {ext }}$ rate for larger $E$. This is due to keyreactions for ammonia combustion, most relevant for ammonia-dominant fuel blends, which are not included in GRI Mech3.0 (Okafor et al., 2018). This can be improved by introducing some essential reactions involving the $\mathrm{NH}_{\mathrm{i}}$ radicals as verified when comparing the results of Okafor's mechanism against GRI Mech 3.0 in this study. UCSD mechanism and Okafor's mechanism show a similar trend with the exception of the $\phi=0.7$ condition. This divergence appeared to increase for larger $E$ and might thus be attributed to the chemistry subset related to the $\mathrm{NH}_{\mathrm{i}}$ as they become of larger importance for a larger content of ammonia. From a reaction path analysis in lean $\mathrm{NH}_{3} /$ air premixed flames, reaction paths corresponding to $\mathrm{HNO}$ production $\left(\mathrm{NH}_{2}, \mathrm{NH} \rightarrow \mathrm{HNO}\right)$ and 
reduction to NO appear to have a more predominant role than in stoichiometric and rich flames (Kobayashi et al., 2019). Moreover, the reactions associated with those paths have different reaction constants in the two mechanisms and might explain to some extent the differences observed. Reactions in the set of the $\mathrm{NH}_{\mathrm{i}}-\mathrm{CH}_{\mathrm{i}}$ interactions might also be involved but have a lower impact on the overall chemistry. Further improvement of the detailed chemistry is expected especially in the lean region for $\mathrm{NH}_{3} / \mathrm{CH}_{4}$ mixed fuels.

\subsection{Extinction stretch rate of counterflow non-premixed flames}

Experimental results of extinction stretch rates of counterflow non-premixed flames, $\varepsilon_{e x t}$, are presented in Fig.6 for various $E$ with numerical results. Actually, due to flame weakness and strong buoyancy effect, the flame could not be stabilized for $E$ over 0.7. Comparing experimental results and numerical ones, it can be observed that Okafor's mechanism shows the best fit across the full range of conditions considered. The UCSD mechanism provides good fitting to the experimental $\varepsilon_{\text {ext }}$ for $E$ values below 0.15 . However, it overestimates the flame extinction stretch rates for larger $E$ values. This discrepancy may be related to the HNO production-consumption path, as already discussed for the extinction stretch rate of counterflow premixed flames, or attributed to reactions of interactions between hydrocarbons and nitrogen species. Indeed, this inconsistency is larger in the range of $E=0.2-0.8$, than for pure $\mathrm{CH}_{4}$ or pure $\mathrm{NH}_{3}$ cases, supporting the latter assumption. It can be assumed that for the same reasons as for counterflow premixed flames, the extinction stretch rate of counterflow diffusion flames was underestimated by GRI Mech3.0 in higher $E$ conditions and by Tian's mechanisms in smaller $E$ conditions.

[Figure 6] 
The present study on the extinction stretch rate for both counterflow premixed and non-premixed flames allowed to differentiate between the different detailed mechanisms used. In the non-premixed flame cases, a reasonable fit of extinction stretch rate was obtained with Okafor's mechanism, whereas in the lean premixed flames case, there was no satisfactory fit with any of the four mechanisms considered.

\subsection{FWHM of $\mathrm{OH}$ and $\mathrm{NO}$ profiles in counterflow premixed flames}

Greater discrepancies between results from experiment and numerical simulation could be observed in the premixed twin flame cases for which none of the mechanisms were able to reproduce the experimental trend. Further investigation is thus particularly necessary for those flames. In order to identify the origin of the discrepancy more specifically, the premixed twin flame structure was thus investigated, using $\mathrm{OH}$ and NOPLIF.

In the counterflow premixed twin flames configuration, profiles of temperature and species are symmetric to the stagnation plane as seen in Fig.3. The FWHM parameter corresponds to the distance between the apparitions of the radicals in the two flames front. This parameter, as well as the distance between two flames in counterflow twin flames configuration, varies with $\varepsilon, \phi$ and $E$. FWHM of $\mathrm{OH}$ and $\mathrm{NO}$ profiles can thus be associated with the speed of formation and consumption of these species. Thus, comparisons of the FWHM experimental values with the numerical ones of different mechanisms allow for the validation of those mechanisms for stretched premixed $\mathrm{NH}_{3} / \mathrm{CH}_{4} /$ air twin flames. Moreover, it allows for the identification of the associated reactions' subsets that require improvement.

The relationship between the mole fraction profiles and the measured fluorescence intensity profiles is usually not directly proportional as discussed in (Eckbreth, 1996) and 
(Battles and Hanson, 1995). Dependence of the fluorescence on temperature and quenching is a major issue. In the case of $\mathrm{OH}$ radicals, the dependence on temperature, through the Boltzmann fraction, can be considered as neglectable due to the selection of appropriate excitation wavelengths. Indeed, in the flames considered in this study, the $\mathrm{OH}$ radicals were present in a region over which temperature varied in the range $1400 \mathrm{~K}$ to $2100 \mathrm{~K}$. Following the work of McManus et al. (1995), and for this range of temperature, the dependence on temperature of fluorescence intensity for the $\mathrm{OH} Q_{1}(6)$ transition can be neglected.

As for quenching, the variation of the fluorescence intensity was observed with variation of the laser energy output by taking the average intensity of fluorescence image for different laser energy values. It could be observed that in the condition of the experiment, the laser energy (about $12 \mathrm{~mJ}$ per shot) for OH-PLIF was large enough to reach the saturated fluorescence regime. In those conditions, quenching might be neglected and fluorescence intensity $F$ can be expressed as in Eq. (4) as derived in Eckbreth (1996):

$$
\mathrm{F}=\mathrm{C} N_{O H} F_{J} \propto X_{O H} \frac{P}{k T}
$$

where $X$ is the mole fraction, $P$ the pressure, $k$ the Boltzmann constant and $T$ the temperature. The coefficient $C$ depends on several experimental parameters and Einstein coefficients for stimulated and spontaneous emission and absorption but remains constant along the flame front. $N_{O H}$ is the $\mathrm{OH}$ particle density and $F_{J}$ is the Boltzmann fraction, which is considered to be constant as previously stated. The proportional relationship between $F$ and $X_{O H} P / k T$ is thus obtained along the burner axis across the flame front. This allows for the comparison of the FWHM of the experimental $\mathrm{OH}$ fluorescence profiles with the ones of the $X_{O H} P / k T$ quantity, which is obtained from the numerical simulation from the selected kinetic mechanisms. 
For $\mathrm{NO}$, the laser energy was much lower than for $\mathrm{OH}$, and the study on the variation of the NO fluorescence intensity for different laser energies showed that the fluorescence regime was linear. In this regime, fluorescence intensity can be related to the mole fraction of NO, $X_{N O}$, as introduced in Eq. (5) (Eckbreth, 1996):

$$
\mathrm{F}=\mathrm{C} X_{N O} \frac{P}{k T} F_{J} I \Phi
$$

where $C$ is constant across the flame front, $I$ is laser excitation irradiance, $\Phi$ the fluorescence efficiency. The fluorescence signal was corrected for laser sheet nonuniformity and normalized taking into account the different laser energy for the different measurements allowing comparison between them. This normalized fluorescence, $f$, relation with the NO mole fraction $X_{N O}$ is then expressed as in Eq. (6) :

$$
f \propto X_{N O} \frac{P}{k T} F_{J} \Phi_{J}
$$

Several rotational levels, $J$, being excited here, the expression can be rewritten for the sum over the different excited states yielding:

$$
f \propto X_{N O} \frac{P}{k T} \sum_{J} F_{J} \Phi_{J}
$$

The right-hand side of Eq. (7) was calculated from numerical simulations using the selected chemical mechanisms. The quenching rate, $Q$, was estimated using the quenching cross-section values from Paul et al. (1995) and Renard et al. (1999), and the temperature and species mole fraction distributions obtained from simulations. The Boltzmann fraction was calculated using the expression by Eckbreth (1996) and the NO spectrometry constants from van Gessel et al. (2013) and Huber and Herzberg (1979). Greater details on these calculations are available in the supplementary material section. [Figure 7] and [Figure 8]

To compare the FWHM of $\mathrm{OH}$ and $\mathrm{NO}$ in counterflow premixed flames obtained numerically and experimentally, those data were plotted against each other for each 
mechanism and correlations were examined as shown in Fig.7. Determination coefficients, $R^{2}$, were also calculated for lean, stoichiometric and rich conditions as shown in Fig.8. The plots cover values of equivalence ratio, $\phi$, of $0.8,1.0,1.1$ and 1.2 and a fuel mixing ratio, $E$, of $0,0.15,0.30,0.60$, and 1.0 in this PLIF measurements. The experimental uncertainty in terms of quantitative evaluation of $\mathrm{OH}$ and NO FWHMs from PLIF measurements is represented by the error bars in Fig.7. The bulk velocities at the burner outlet, $U$, were set between $30 \%$ and $60 \%$ of their value at extinction, corresponding to conditions at which the flame is the least sensitive to perturbations. A summary of the conditions and uncertainties is available in the supplementary material section.

Although data are scattered, the characteristics of the selected mechanisms can be seen in Fig.7 as well as common features depending on $\phi$ values in Fig.8. Prior to the discussion on the different mechanisms, effects of $\phi$ values on $R^{2}$ are considered. As seen in Fig.8, for fuel lean condition $(\phi=0.8), R^{2}$ is smaller than for richer conditions, corresponding to the previous observations on the extinction stretch rate of lean flames shown in Figs. 5a and b. On the other hand, for stoichiometric and rich cases, $R^{2}$ increases, indicating stronger correlation, also observed for the extinction stretch rate for the rich flame shown in Fig.5c. Those corresponding trends obtained from the analysis of the FWHMs of $\mathrm{OH}$ and $\mathrm{NO}$ and extinction stretch rate, indicate the potential of the present analysis based on PLIF measurements for improving detailed chemistry.

A more detailed discussion on each chemistry can be made as follows. Linear regression was obtained from the data using the method of least square and are represented in Fig.7. The correlation curves for OH radical represented on Fig.7.a. are all located over the $y=x$ line, corresponding to the equality between the experimental and numerical FWHM, with the exception of Tian's mechanism. Tian's mechanism only 
tends to predict the apparition of the $\mathrm{OH}$ radical downstream to the experimental results for most of the cases observed, featuring the same trend for $\mathrm{OH}$ production as the one observed for the extinction stretch rate. It is then followed by GRIMech 3.0, Okafor's mechanism and UCSD mechanism when gradually going above the $y=x$ line, which all, in the same order, over-predicted the extinction stretch rate in Fig.5. For NO in Fig.7.b., all the correlation curves are located above the $y=x$ line, showing a general overprediction of NO production too. The correlation curves are closer to each other with few differences in the NO prediction by the different mechanisms. While Tian's gave particularly scattered data in the case of $\mathrm{OH}$, it correlates better for $\mathrm{NO}$ at the opposite of Okafor's mechanism for which data are much more scattered for NO, suggesting some lacks in the nitrogen chemistry.

In this study, comparisons of the experimental FWHM of OH and NO-PLIF to numerical results were proposed for detailed chemistry evaluation. $\mathrm{NH}, \mathrm{CH}$, and $\mathrm{CH}_{2} \mathrm{O}$ are other species of interest for $\mathrm{NH}_{3} / \mathrm{CH}_{4}$ flames which are accessible by PLIF measurements. Extension of this study to those species will be investigated in future work.

\section{Conclusions}

Both premixed and non-premixed $\mathrm{NH}_{3} / \mathrm{CH}_{4}$ flames were investigated in the counterflow configurations. Extinction stretch rates were obtained experimentally over a wide range of $\mathrm{NH}_{3}$ mixing ratios and equivalence ratios. Four selected detailed reaction mechanisms were then compared to the experimental results. It was observed that:

(1) In premixed flames, all the mechanisms investigated were inadequate for predicting the extinction stretch rate, specifically in the lean region.

(2) In non-premixed flames, Okafor's mechanism was well-validated for extinction stretch rate criteria. 
$\mathrm{OH}$ and NO-PLIF measurements were performed for quantitative determination of the FWHM of the profiles of $\mathrm{OH}$ and $\mathrm{NO}$ for counterflow premixed flames. They were then compared with those obtained by numerical analysis using four mechanisms. The following results were obtained:

(1) The lower determination coefficients, $R^{2}$, in the lean region for both $\mathrm{OH}$ and NO suggest that further investigation in this region is necessary for mechanisms improvement.

(2) All the detailed chemistries, at the exception of Tian's mechanism for OH, overpredicted the apparition of both $\mathrm{OH}$ and NO. Tian's showed scattered trend and under-predicted $\mathrm{OH}$ apparition in the flame. GRIMech 3.0 showed a wellcorrelated trend for small $E$ but failed to reproduce the pure $\mathrm{NH}_{3}$ case. Okafor's mechanism and UCSD mechanism provided a better prediction of the experimental trend though overestimating the apparition of both $\mathrm{OH}$ and $\mathrm{NO}$ in the flame.

WORD COUNTS: 5608

\section{Acknowledgments:}

This work was supported by the Council for Science, Technology and Innovation (CSTI), the Cross-ministerial Strategic Innovation Promotion Program (SIP) "Energy Carriers" (Funding agency: Japan Science and Technology Agency (JST)). A part of the work was carried out under the Collaborative Research Project of the Institute of Fluid Science, Tohoku University and in the framework of the Japan-France International Associated Laboratory (LIA) ELyT Global.

\section{References}


Avery, W.H. 1988. A role for ammonia in the hydrogen economy. Int. J. Hydrogen Energy, 13, 761.

Banna, S.M., and Branch, M.C. 1981. Mixing and reaction of $\mathrm{NH}_{3}$ with $\mathrm{NO}$ in combustion products. Combust. Flame, 42, 173.

Barbas, M., Costa, M., Vranckx, S., and Fernandes, R.X. 2013. Experimental and kinetic modeling study of $\mathrm{CO}$ and $\mathrm{NO}$ formation under oxy-fuel conditions. Combust. Flame, 162, 1294.

Battles, B.E., and Hanson, R.K. 1995. Measurements NO and OH mole fraction flames : Fluorescence and Experimental. J. Quant. Spectrosc. Radiat. Transf., 54, 521.

Brackmann, C., Alekseev, V.A., Zhou, B., Nordström, E., Bengtsson, P.E., Li, Z., Aldén, M., and Konnov, A.A. 2016. Structure of premixed ammonia + air flames at atmospheric pressure: laser diagnostics and kinetic modeling. Combust. Flame, 163, 370 .

Brackmann, C., Nilsson, E.J.K., Nauclér, J.D., Aldén, M., and Konnov, A.A. 2018. Formation of $\mathrm{NO}$ and $\mathrm{NH}$ in $\mathrm{NH}_{3}$-doped $\mathrm{CH}_{4}+\mathrm{N}_{2}+\mathrm{O}_{2}$ flame: experiments and modelling. Combust. Flame, 194, 278.

Chelliah, H.K., Law, C.K., Ueda, T., Smooke, M.D., and Williams, F.A. 1990. An experimental and theoretical investigation of the dilution, pressure and flow-field effects on the extinction condition of methane-air-nitrogen diffusion flames. Proc. Combust. Inst., 23, 503.

CHEMKIN-PRO Release 15101, Reaction Design 2010.

Choi, S., Lee, S., and Kwon, O.C. 2015. Extinction limits and structure of counterflow nonpremixed hydrogen-doped ammonia/air flames at elevated temperatures. Energy, 85, 503.

Colson, S., Hayakawa, A., Kudo, T., and Kobayashi, H. 2016. Extinction characteristics of ammonia/air counterflow premixed flames at various pressures. J. Therm. Sci. Technol., 11, JTST0048.

Davis, M.P., Fleming, J.W., Williams, B.A., and Ladouceur, H.D. 1999. Flow field considerations for counter flow burners. Proc. Fall Tech. Meet. East. States Sect. Combust. Inst., 200.

Eckbreth, A.C. 1996. Laser diagnostics for combustion temperature and species Combustion. In Sirignano, W.A. (Ed.), Combustion Science and Technology Book Series, Gordon and Breach, Amsterdam, Vol. 3.

Escudié, D., Haddar, E., and Brun, M. 1999. Influence of strain rate on a premixed turbulent flame stabilized in a stagnating flow. Exp. Fluids, 27, 533.

Fairbanks, D.F., and Wilke, C.R. 1950. Diffusion coefficients in multicomponent gas mixtures. Ind. Eng. Chem., 42, 471. 
Grand, D., Le Brun, C., Vidil, R., and Wagner, F. 2016. Electricity production by intermittent renewable sources: a synthesis of French and German studies. Eur. Phys. J. Plus, 131, 1.

Hayakawa, A., Goto, T., Mimoto, R., Arakawa, Y., Kudo, T., and Kobayashi, H. 2015. Laminar burning velocity and Markstein length of ammonia/air premixed flames at various pressures. Fuel, 159, 98.

Hubert, K.P., and Herzberg, G. 1979. Constants of diatomic molecules. In Molecular Spectra and Molecular Structure, Van Nostrand Reinhold Company, New York, Vol. 4.

Ichikawa, A., Hayakawa, A., Kitagawa, Y., Kunkuma Amila Somarathne, K.D., Kudo, T., and Kobayashi, H. 2015. Laminar burning velocity and Markstein length of ammonia/hydrogen/air premixed flames at elevated pressures. Int. J. Hydrogen Energy, 40, 9570.

Kobayashi, H., Hayakawa, A., Somarathne, K.D.K.A., and Okafor, E.C. 2019. Science and technology of ammonia combustion. Proc. Combust. Inst., 37, 109.

Kobayashi, H., and Kitano, M. 1991. Dimensional effects of nozzle-type burner on flow fields and extinction of counterflow twin flames. Trans. Japan Soc. Mech. Engrs., 57, 363 (in Japanese).

Kojima, Y. 2015. Hydrogen storage and transportation using ammonia. Hyomen Kagaku, 36, 583.

Ku, J.W., Choi, S., Kim, H.K., Lee, S., and Kwon, O.C. 2018. Extinction limits and structure of counterflow nonpremixed methane-ammonia/air flames. Energy, 165, 314.

Kumar, P., and Meyer, T.R. 2013. Experimental and modeling study of chemical-kinetics mechanisms for H2-NH3-air mixtures in laminar premixed jet flames. Fuel, 108, 166.

Kurata, O., Iki, N., Inoue, T., Matsunuma, T., Tsujimura, T., Furutani, H., Kawano, M., Arai, K., Okafor, E.C., Hayakawa, A., and Kobayashi, H. 2019. Development of a wide range-operable, rich-lean low-NOx combustor for NH3 fuel gas-turbine power generation. Proc. Combust. Inst., 37, 4587.

Law, C.K., Zhu, D.L., and Yu, G. 1986. Propagation and extinction of stretched premixed flames. Symp. Combust., 21, 1419.

Law, C.K. 2006. Combustion Physics In Press, C.U. (Ed.) Cambridge.

Lhuillier, C., Brequigny, P., Lamoureux, N., Contino, F., and Mounaïm-Rousselle, C. 2020. Experimental investigation on laminar burning velocities of ammonia/hydrogen/air mixtures at elevated temperatures. Fuel, 263, 116653. 
Lindstedt, R.P., Luff, D.S., and Whitelaw, J.H. 2005. Velocity and strain-rate characteristics of opposed isothermal flows. Flow, Turbul. Combust., 74, 169.

Mathieu, O., and Petersen, E.L. 2015. Experimental and modeling study on the hightemperature oxidation of ammonia and related NOx chemistry. Combust. Flame, 162, 554.

McManus, K., Yip, B., and Candel, S. 1995. Emission and laser-induced fluorescence imaging methods in experimental combustion. Exp. Therm. Fluid Sci., 10, 486.

Mei, B., Zhang, X., Ma, S., Cui, M., Guo, H., Cao, Z., and Li, Y. 2019. Experimental and kinetic modeling investigation on the laminar flame propagation of ammonia under oxygen enrichment and elevated pressure conditions. Combust. Flame, 210, 236.

Mendiara, T., and Glarborg, P. 2009. Ammonia chemistry in oxy-fuel combustion of methane. Combust. Flame, 156, 1937.

Okafor, E.C., Naito, Y., Colson, S., Ichikawa, A., Kudo, T., Hayakawa, A., and Kobayashi, H. 2018. Experimental and numerical study of the laminar burning velocity of $\mathrm{CH} 4-\mathrm{NH} 3-$ air premixed flames. Combust. Flame, 187, 185.

Okafor, E.C., Somarathne, K.D.K.A., Hayakawa, A., Kudo, T., Kurata, O., Iki, N., and Kobayashi, H. 2019. Towards the development of an efficient low-NOx ammonia combustor for a micro gas turbine. Proc. Combust. Inst., 37, 4597.

Okafor, E.C., Naito, Y., Colson, S., Ichikawa, A., Kudo, T., Hayakawa, A., and Kobayashi, H. 2019. Measurement and modelling of the laminar burning velocity of methane-ammonia-air flames at high pressures using a reduced reaction mechanism. Combust. Flame, 204, 162.

Paul, P.H., Carter, C.D., Gray, J.A., Durant, J.L., Thoman, J.W., and Furlanetto, M.R. 1995. Correlations for the NO $\mathrm{A}^{2} \Sigma+\left(\mathrm{v}^{\prime}=0\right)$ electronic quenching cross-section. Sandia Rep. SAND94-8237 UC-1423, SAND94-823.

Rahinov, I., Goldman, A., and Cheskis, S. 2006. Absorption spectroscopy diagnostics of amidogen in ammonia-doped methane/air flames. Combust. Flame, 145, 105.

Renard, P.H., Rolon, J.C., Thévenin, D., and Candel, S. 1999. Investigations of heat release, extinction, and time evolution of the flame surface, for a non-premixed flame interacting with a vortex. Combust. Flame, 117, 189.

Seshadri, K., and Williams, F.A. 1978. Laminar flow between parallel plates with injection of a reactant at high Reynolds number. Int. J. Heat Mass Transf., 21, 251.

Smith, G.P., Golden, D.M., Frenklach, M., Moriarty, N.W., Eiteneer, B., Goldenberg, M., Bowman, C.T., Hanson, R.K., Song, S., Gardiner, W.C., Lissianski, Jr., V. V., and Qin, Z. 2000. GRIMech 3.0.

Somarathne, K.D.K.A., Okafor, E.C., Hayakawa, A., and Kobayashi, H. 2019. Emissions characteristics of turbulent non-premixed $\mathrm{CH}_{4} / \mathrm{NH}_{3} /$ air Swirl flames through a rich- 
lean gas turbine like combustor at high pressure. In, Proceedings of the 12th AsiaPacific Conference on Combustion, ASPACC2019. Fukuoka, ASPACC2019-1189.

Sullivan, N., Jensen, A., Glarborg, P., Day, M.S., Grcar, J.F., Bell, J.B., Pope, C.J., and Kee, R.J. 2002. Ammonia conversion and NOx formation in laminar coflowing nonpremixed methane-air flames. Combust. Flame, 131, 285.

Takita, K., Yamazaki, H., Takuya, U., and Masuya, G. 2006. Extinction Karlovitz numbers of premixed counterflow flames under various pressure. Combust. Sci. Technol., 178, 1649.

Tian, Z., Li, Y., Zhang, L., Glarborg, P., and Qi, F. 2009. An experimental and kinetic modeling study of premixed $\mathrm{NH}_{3} / \mathrm{CH}_{4} / \mathrm{O}_{2} / \mathrm{Ar}$ flames at low pressure. Combust. Flame, 156, 1413.

University California of San Diego 2016. Chemical-kinetic mechanisms for combustion applications. 2016-12-14 and 2004-12-09 versions.

Valera-Medina, A., Xiao, H., Owen-Jones, M., David, W.I.F., and Bowen, P.J. 2018. Ammonia for power. Prog. Energy Combust. Sci., 69, 63.

van Gessel, A.F.H., Hrycak, B., Jasiński, M., Mizeraczyk, J., van der Mullen, J.J.A.M., and Bruggeman, P.J. 2013. Temperature and NO density measurements by LIF and OES on an atmospheric pressure plasma jet. J. Phys. D. Appl. Phys., 46, 095201.

Xia, Y., Hashimoto, G., Hadi, K., Hashimoto, N., Hayakawa, A., Kobayashi, H., and Fujita, O. 2020. Turbulent burning velocity of ammonia/oxygen/nitrogen premixed flame in O2-enriched air condition. Fuel, 268.

Zieba, M., Brink, A., Schuster, A., Hupa, M., and Scheffknecht, G. 2009. Ammonia chemistry in a flameless jet. Combust. Flame, 156, 1950. 
Table 1. Geometric configurations of the burner employed in this study.

\begin{tabular}{lc}
\hline Study cases & L/D \\
\hline Extinction of premixed twin flames for $\mathrm{NH}_{3} / \mathrm{CH}_{4} /$ air $\left(\right.$ except $\mathrm{NH}_{3} /$ air $)$ & 1.2 \\
Extinction of premixed twin flames for $\mathrm{NH}_{3} /$ air & 1.0 \\
Extinction of non-premixed flames & 1.0 \\
OH-PLIF and NO-PLIF measurements & 1.0 \\
\hline
\end{tabular}

Table 2. Lewis number of ammonia and methane mixtures following work by Fairbank and Wilke (1950) and transport and thermal data from Okafor et al. (2018).

\begin{tabular}{lcc}
\hline Equivalence ratio & $\mathbf{0 . 8}$ & $\mathbf{1 . 2}$ \\
\hline Methane/air & 0.96 & 1.10 \\
Ammonia/air & 0.94 & 1.09 \\
\hline
\end{tabular}




\section{List of figures}

Figure 1. Schematics of the experimental setup and flame direct visualization for $E=0.15$ : (a) premixed twin flames, $\phi=1.0, \varepsilon=690 \mathrm{~s}^{-1}$; (b) non-premixed flame, $\varepsilon=150 \mathrm{~s}^{-1}$.

Figure 2. Measurement of the velocity at the burner outlet: example of $\mathrm{CH}_{4} /$ air premixed twin flames at $\phi=0.8, U=210.4 \mathrm{~cm} / \mathrm{s}, L / D=1.0$ : (a) measurement of the axial velocity at the burner outlet, $U_{z}$; (b) measurement of the radial gradient, $g_{r}$.

Figure 3. Normalized $\mathrm{OH}$ and NO-PLIF intensities from experiment and numerical simulation with the mechanism from Okafor et al. (2018), for $\mathrm{NH}_{3} /$ air premixed twin flames at $\phi=1.1, \mathrm{U}=23.1 \mathrm{~cm} / \mathrm{s}$. FWHM of NO-PLIF is represented by a blue arrow.

Figure 4. Experimental extinction stretch rate of $\mathrm{NH}_{3} / \mathrm{CH}_{4} /$ air premixed twin flame for equivalence ratios between 0.6 and 1.4 , for $E=0$ in square, $E=0.15$ in diamonds, $E=$ 0.30 in triangles, $E=0.60$ in crosses, $E=1.0$ in circles.

Figure 5. Extinction stretch rate of $\mathrm{NH}_{3} / \mathrm{CH}_{4} /$ air premixed twin flames for various $E$ : (a) $\phi=0.7$; (b) $\phi=0.9$; (c) $\phi=1.2$. Black crosses represent the present experimental results and experimental trend is denoted by black line. Numerical simulations are represented in color lines.

Figure 6. Extinction stretch rate of $\mathrm{NH}_{3} / \mathrm{CH}_{4}$-air non-premixed flame for various $E$. Experimental results are represented by crosses, numerical results by lines.

Figure 7. Correlation plots for the four mechanisms: (a) OH FWHM; (b) NO FWHM. Experimental uncertainty is represented by the error bars.

Figure 8. Determination coefficient, $R^{2}$, for the four mechanisms per equivalence ratio. 


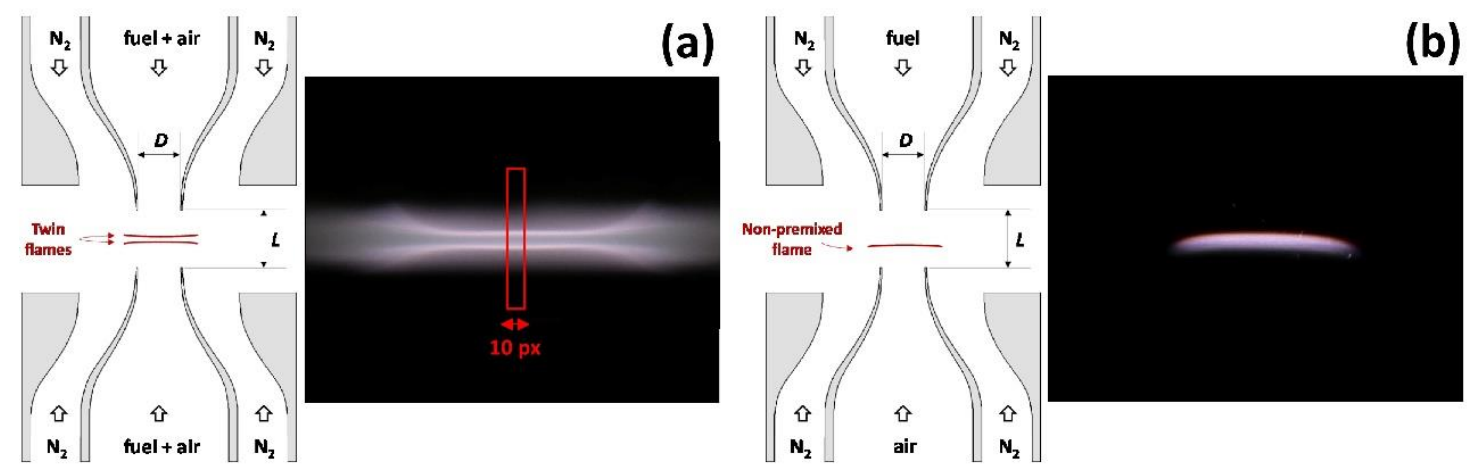

Figure 1. Schematics of the experimental setup and flame direct visualization for $E=0.15$ : (a) premixed twin flames, $\phi=1.0, \varepsilon=690 \mathrm{~s}^{-1}$; (b) non-premixed flame, $\varepsilon=150 \mathrm{~s}^{-1}$. 
(a)

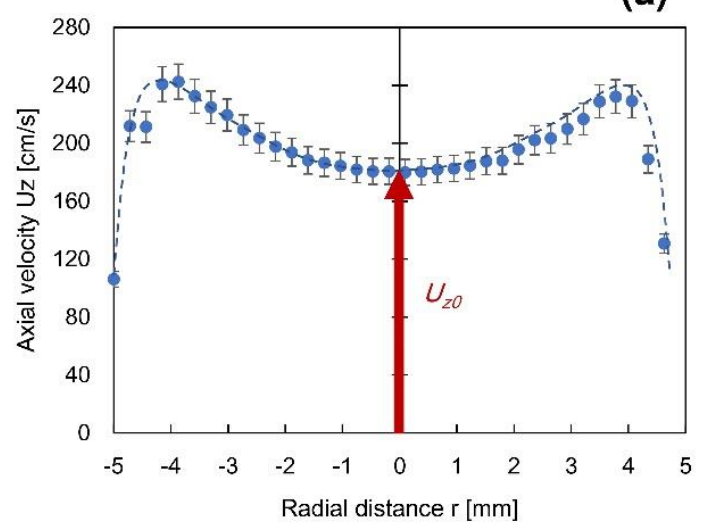

(b)

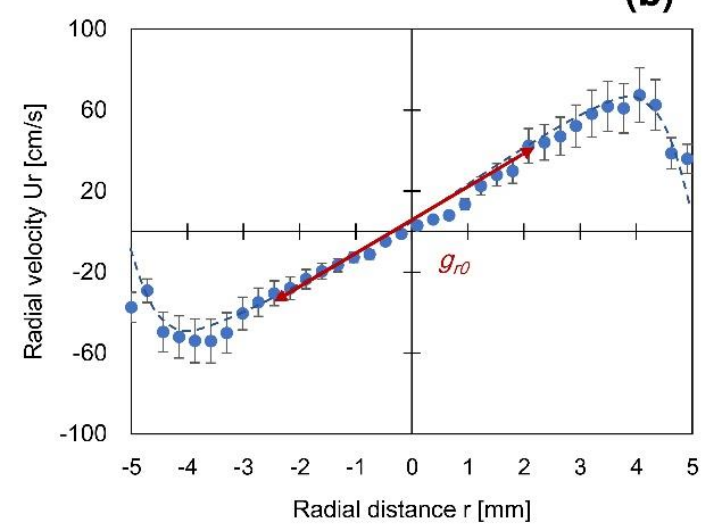

Figure 2. Measurement of the velocity at the burner outlet: example of $\mathrm{CH}_{4} /$ air premixed twin flames at $\phi=0.8, U=210.4 \mathrm{~cm} / \mathrm{s}, L / D=1.0$ : (a) measurement of the axial velocity at the burner outlet, $U_{z 0}$; (b) measurement of the radial gradient, $g_{r} 0$. 


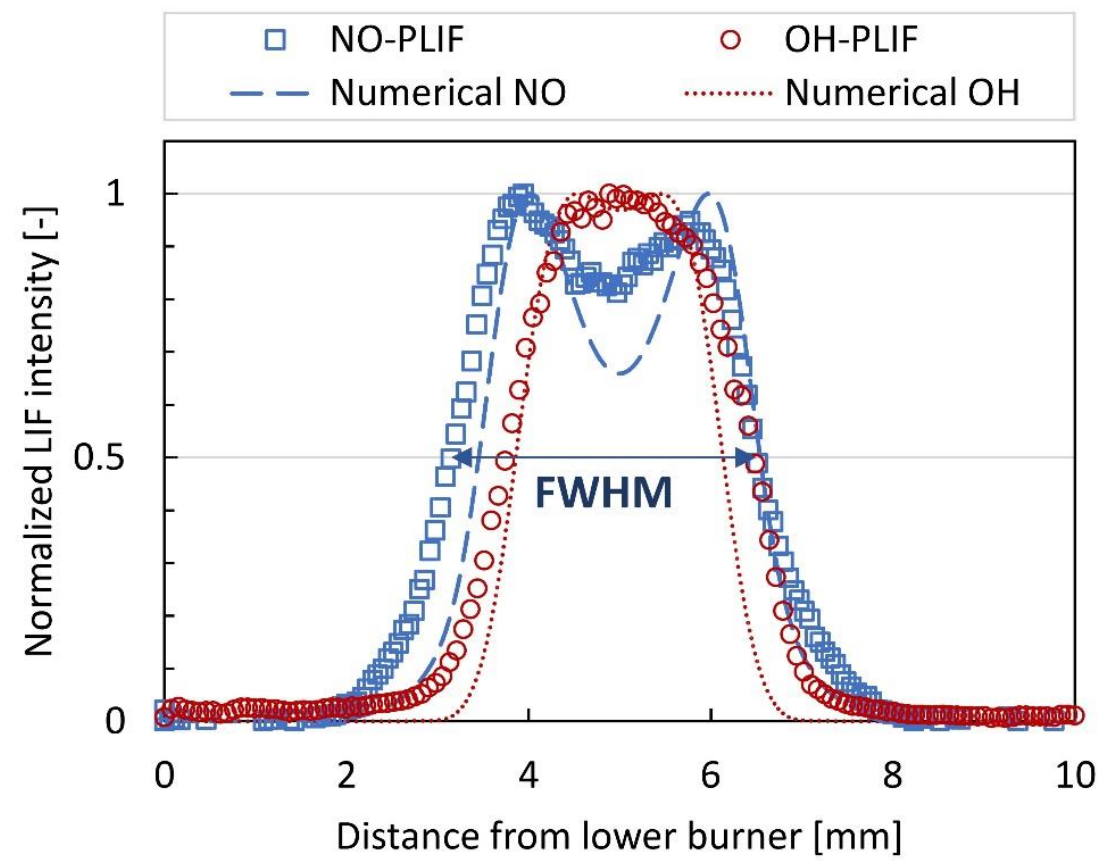

Figure 3. Normalized $\mathrm{OH}$ and NO-PLIF intensities from experiment and numerical simulation with the mechanism from Okafor et al. (2018), for $\mathrm{NH}_{3} /$ air premixed twin flames at $\phi=1.1, U=23.1 \mathrm{~cm} / \mathrm{s}$. FWHM of NO-PLIF is represented by a blue arrow. 


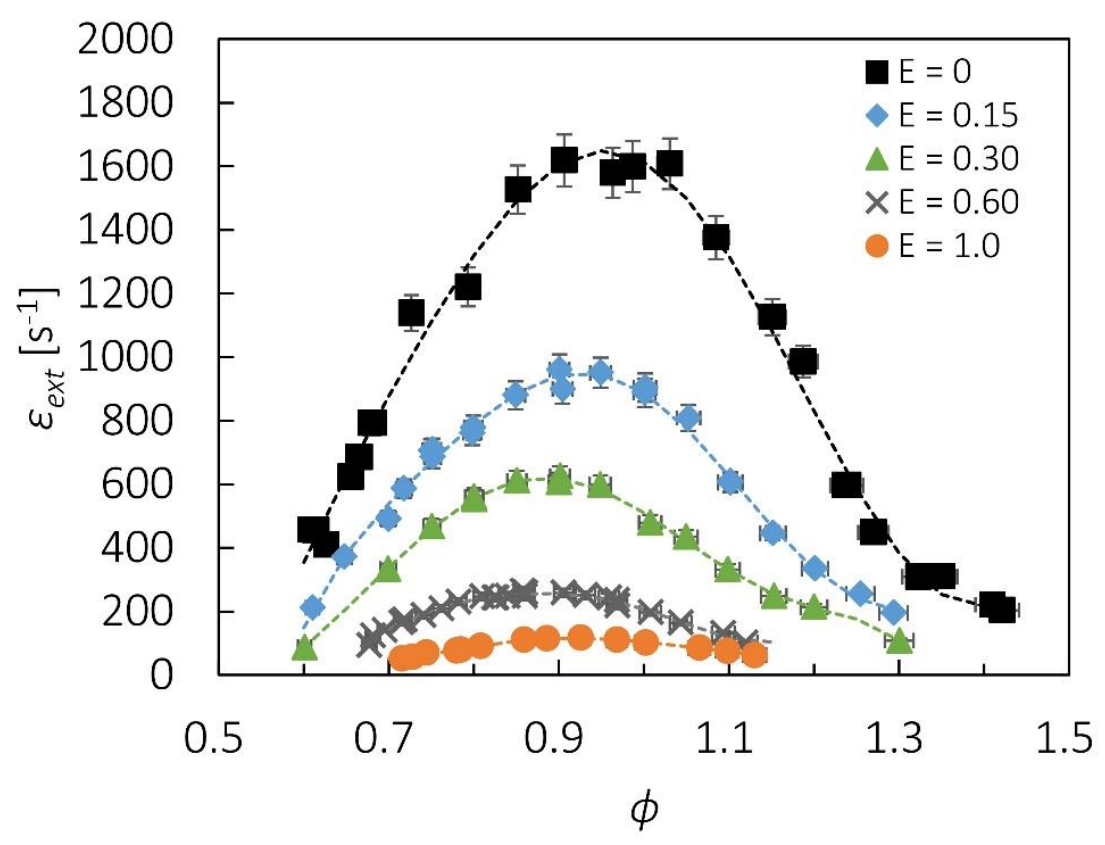

Figure 4. Experimental extinction stretch rate of $\mathrm{NH}_{3} / \mathrm{CH}_{4} /$ air premixed twin flame for equivalence ratios between 0.6 and 1.4 , for $E=0$ in square, $E=0.15$ in diamonds, $E=0.30$ in triangles, $E=0.60$ in crosses, $E=1.0$ in circles. 
(a)
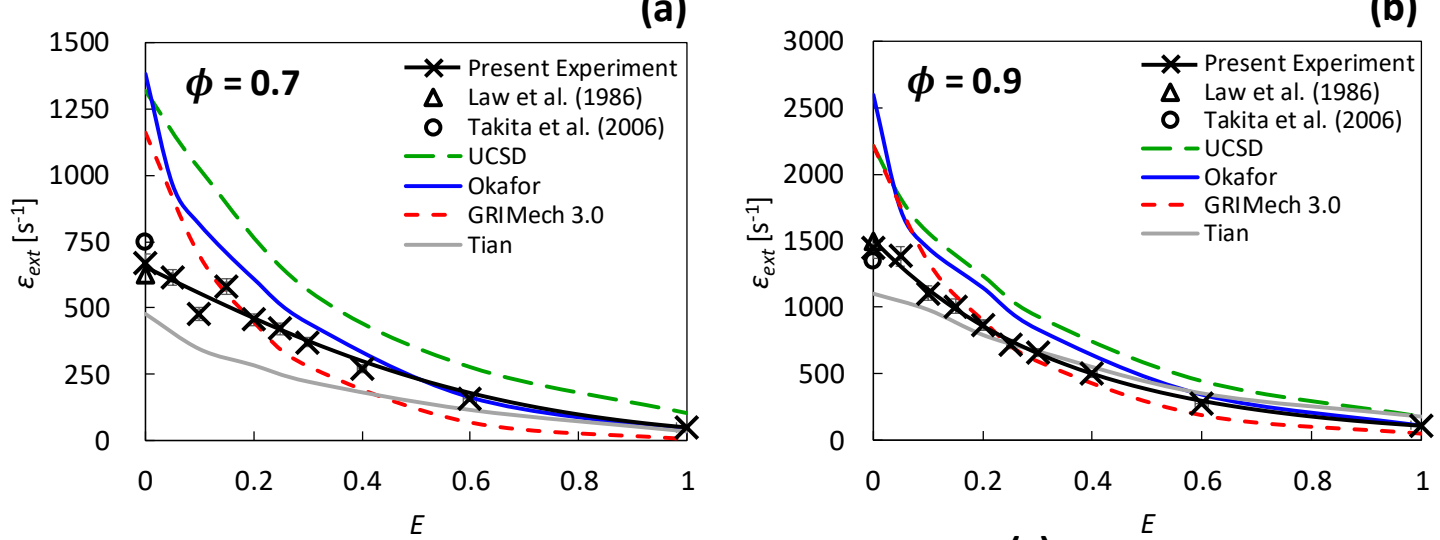

(c)

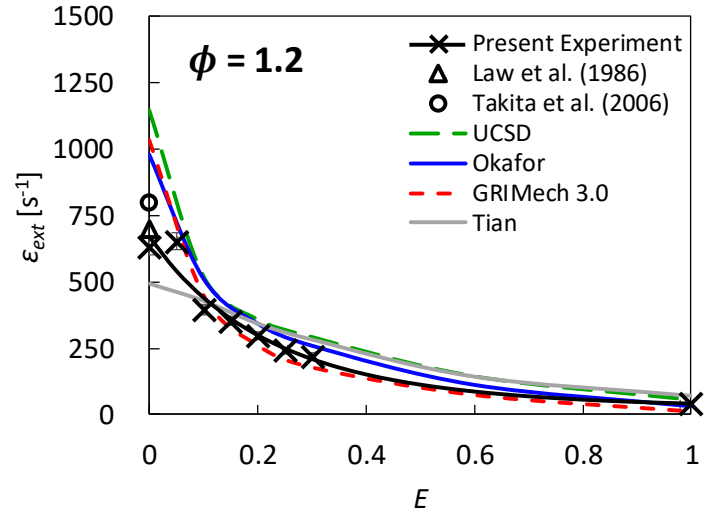

Figure 5. Extinction stretch rate of premixed $\mathrm{NH}_{3} / \mathrm{CH}_{4} /$ air twin flames for various $E$ : (a) $\phi=0.7$; (b) $\phi=0.9$; (c) $\phi=1.2$. Black crosses represent the present experimental result and experimental trend is denoted by black line. Numerical simulations are represented in color lines. 


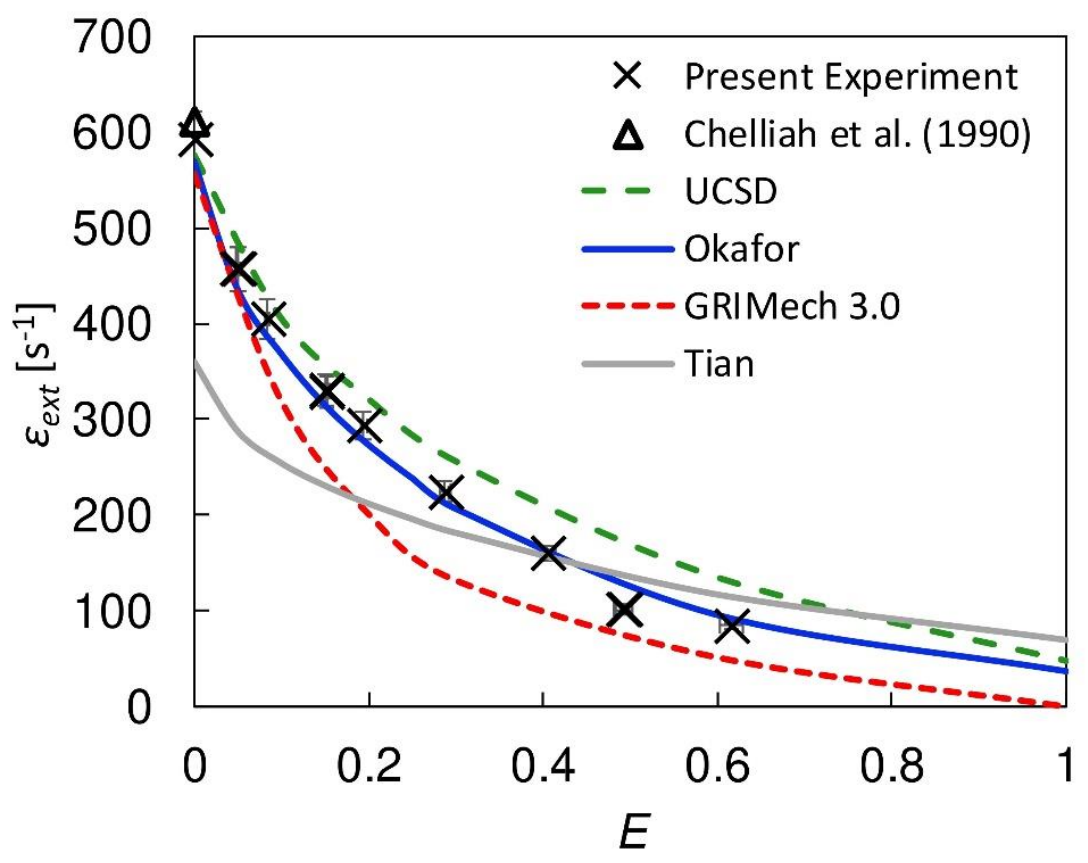

Figure 6. Extinction stretch rate of $\mathrm{NH}_{3} / \mathrm{CH}_{4}$-air non-premixed flame for various $E$. Experimental results are represented by crosses, numerical results by lines. 
(a)

(b)
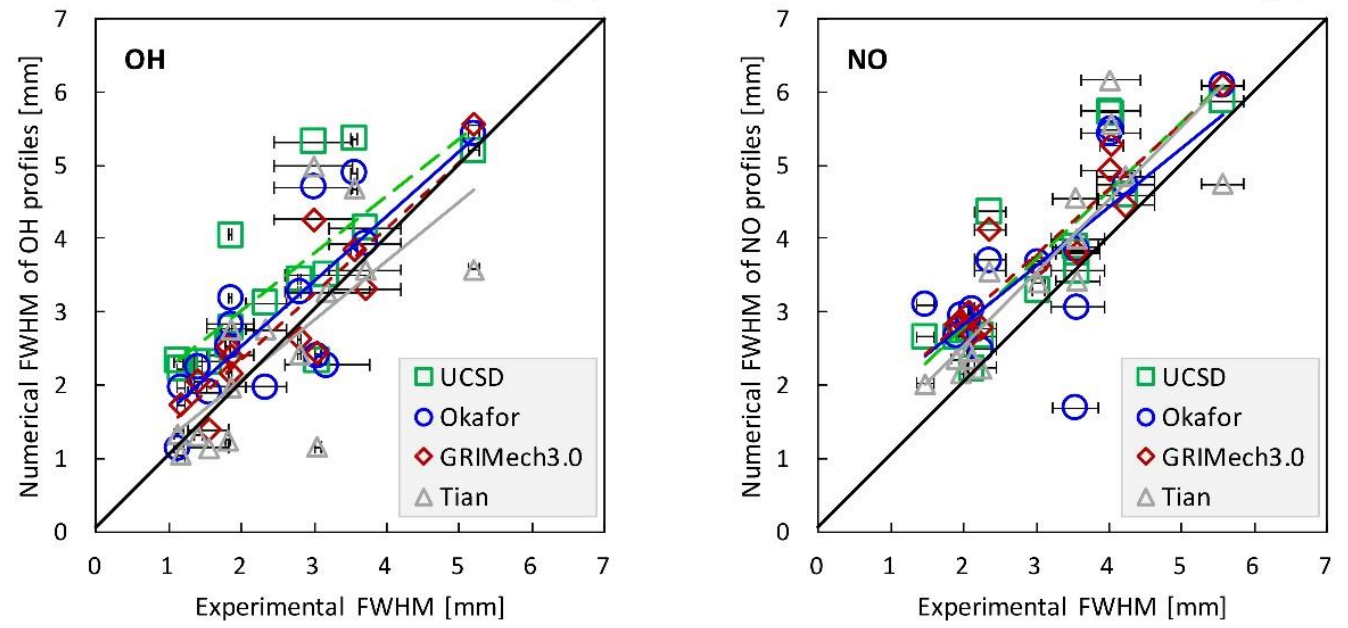

Figure 7. Correlation plots for the four mechanisms: (a) OH FWHM; (b) NO FWHM. Experimental uncertainty is represented by the error bars. 


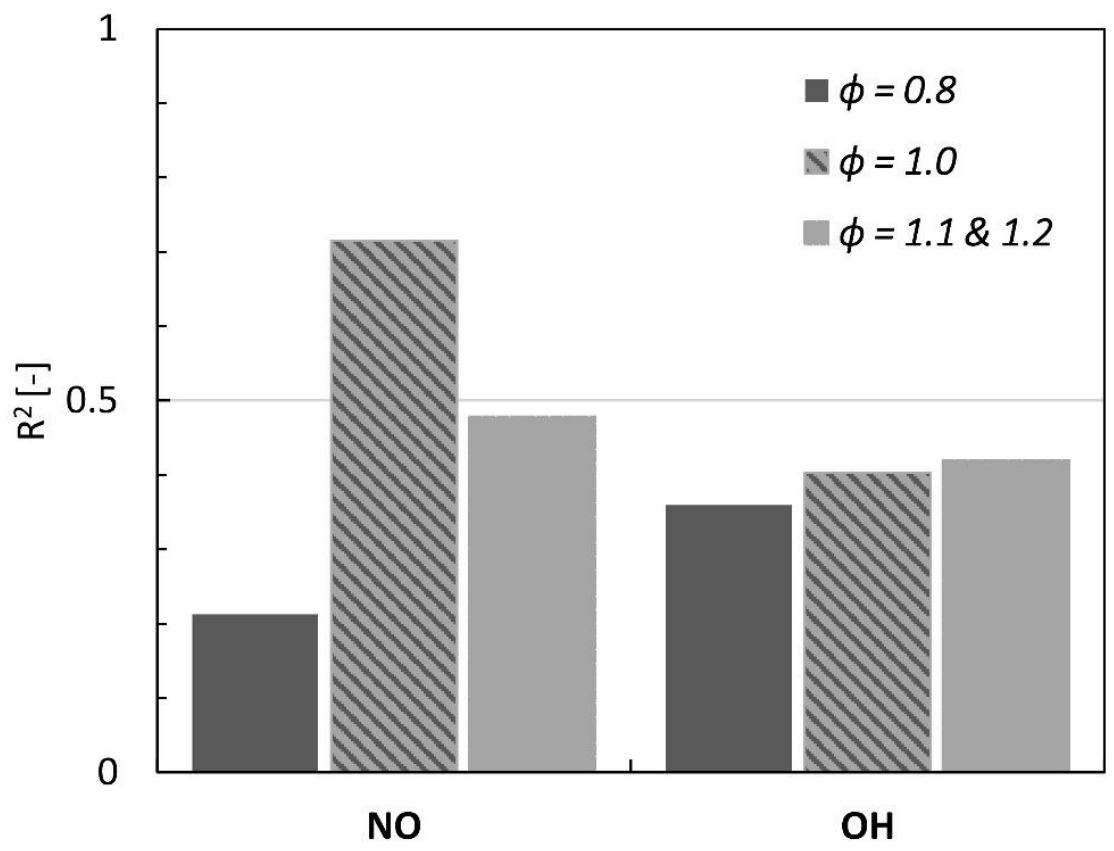

Figure 8. Determination coefficient, $R^{2}$, for the four mechanisms per equivalence ratio. 